: VIROLOGY JOURNAL

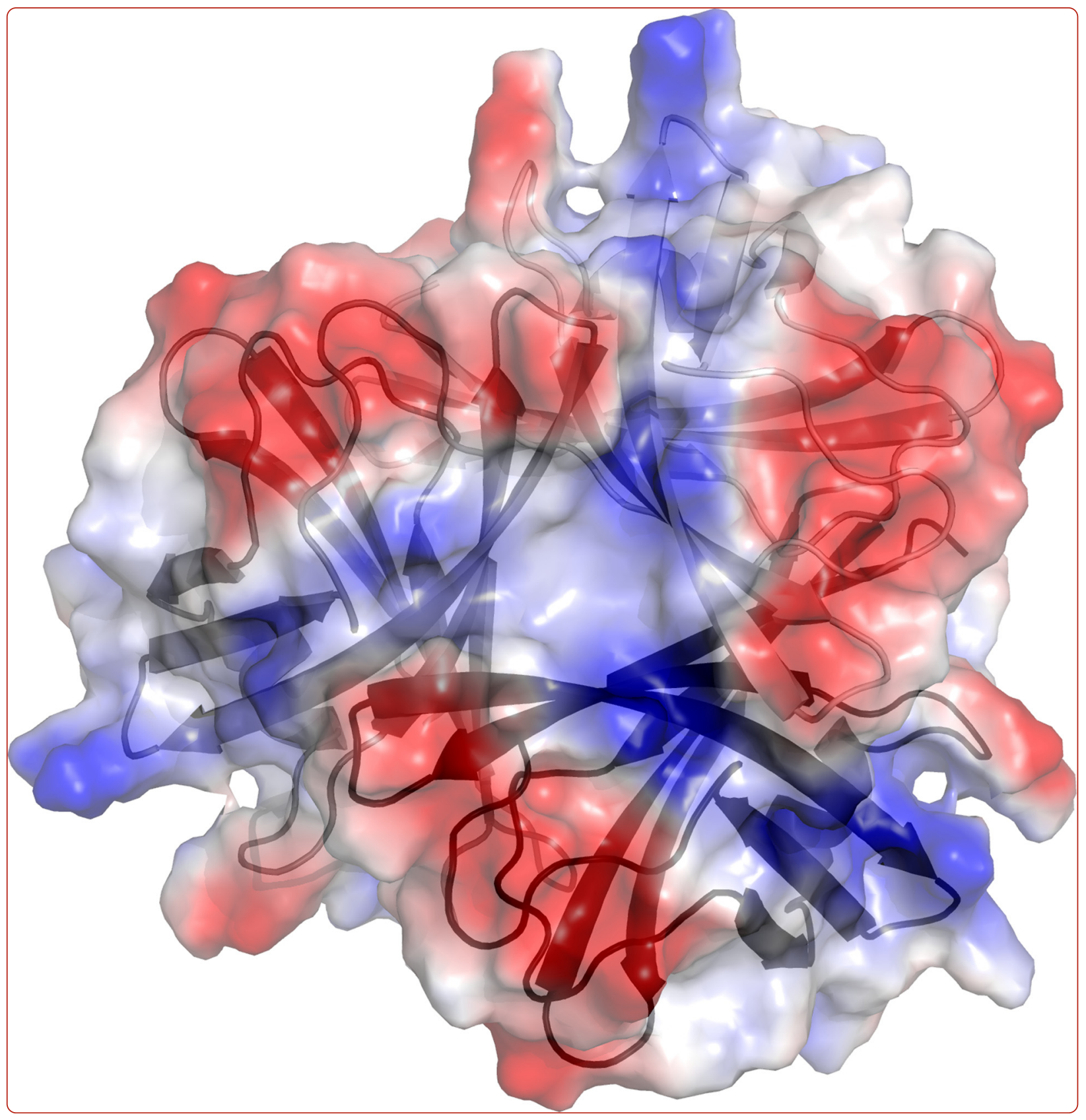

\title{
Crystal structure of the fibre head domain of bovine adenovirus 4 , a ruminant atadenovirus
}

Nguyen et al. 


\title{
Crystal structure of the fibre head domain of bovine adenovirus 4 , a ruminant atadenovirus
}

\author{
Thanh H. Nguyen ${ }^{1}$, Márton Z. Vidovszky², Mónika Z. Ballmann², Marta Sanz-Gaitero ${ }^{1,3}$, Abhimanyu K. Singh ${ }^{1,4}$, \\ Balázs Harrach², Mária Benkö² and Mark J. van Raaij ${ }^{*}$
}

\begin{abstract}
Background: In adenoviruses, primary host cell recognition is generally performed by the head domains of their homo-trimeric fibre proteins. This first interaction is reversible. A secondary, irreversible interaction subsequently takes place via other adenovirus capsid proteins and leads to a productive infection. Although many fibre head structures are known for human mastadenoviruses, not many animal adenovirus fibre head structures have been determined, especially not from those belonging to adenovirus genera other than Mastadenovirus.

Methods: We constructed an expression vector for the fibre head domain from a ruminant atadenovirus, bovine adenovirus 4 (BAdV-4), consisting of amino acids 414-535, expressed the protein in Escherichia coli, purified it by metal affinity and cation exchange chromatography and crystallized it. The structure was solved using single isomorphous replacement plus anomalous dispersion of a mercury derivative and refined against native data that extended to $1.2 \AA$ resolution.

Results: Like in other adenoviruses, the BAdV-4 fibre head monomer contains a beta-sandwich consisting of ABCJ and GHID sheets. The topology is identical to the fibre head of the other studied atadenovirus, snake adenovirus 1 (SnAdV-1), including the alpha-helix in the DG-loop, despite of them having a sequence identity of only $15 \%$. There are also differences which may have implications for ligand binding. Beta-strands $\mathrm{G}$ and $\mathrm{H}$ are longer and differences in several surface-loops and surface charge are observed.

Conclusions: Chimeric adenovirus fibres have been used to retarget adenovirus-based anti-cancer and gene therapy vectors. Ovine adenovirus $7(\mathrm{OAdV}-7)$, another ruminant atadenovirus, is intensively tested as a basis for such a vector. Here, we present the high-resolution atomic structure of the BAdV-4 fibre head domain, the second atadenovirus fibre head structure known and the first of an atadenovirus that infects a mammalian host. Future research should focus on the receptor-binding properties of these fibre head domains.
\end{abstract}

Keywords: Anomalous dispersion, Atadenovirus, Beta-sandwich, Crystallography, Fibre protein, Host-cell recognition, Isomorphous replacement, Ruminants

\section{Background}

Adenoviruses have been isolated from many different vertebrate species [1-4] and, depending on the type, have been associated with respiratory, ocular and gastrointestinal infections $[5,6]$. They are icosahedral nonenveloped viruses with a linear double-stranded DNA genome [7]. The twenty facets of the capsid are formed by the hexon protein (twelve trimers per facet), the

\footnotetext{
*Correspondence: mjvanraaij@cnb.csic.es

'Departamento de Estructura de Macromoleculas, Centro Nacional de Biotecnologia (CNB-CSIC), calle Darwin 3, 28049 Madrid, Spain

Full list of author information is available at the end of the article
}

vertices by a pentameric penton base complex each (Fig. 1a). From each vertex, one or more trimeric fibre proteins protrude [8]. Host cell recognition by human adenoviruses (which are all mastadenoviruses) has been widely studied [9]. Cell recognition and attachment are usually initiated by the fibre protein, via its $\mathrm{C}$-terminal head domain. This attachment triggers a variety of cell responses leading to the activation of cell internalization via endocytosis [10]. When adenoviruses infect a host cell, they introduce their DNA into the host, but do not incorporate it into the host genome. This makes adenovirus a good candidate for gene therapy and other 


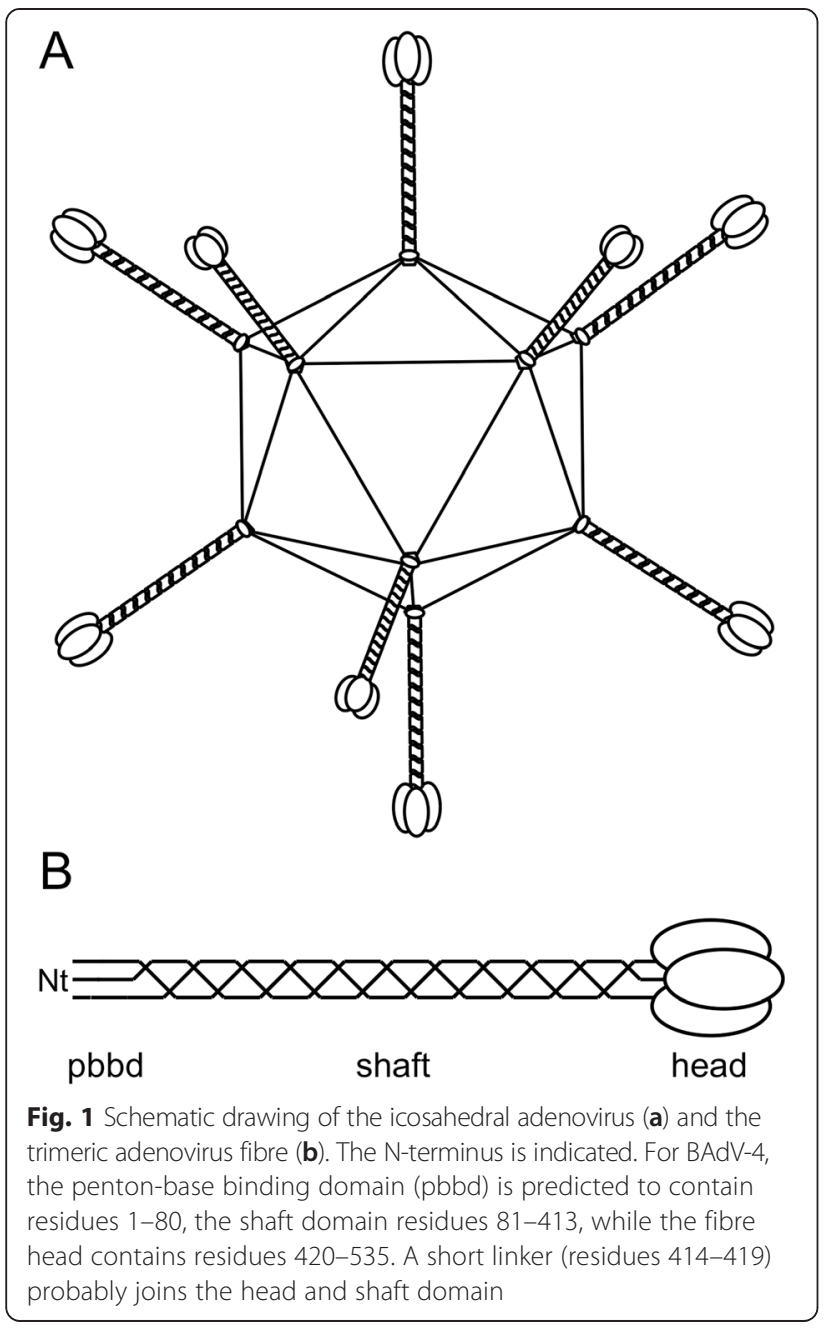

therapeutic treatments and adenovirus is widely studied and used as such [11-18]. Although fibre head structures have been determined for many different human adenovirus fibre heads [7], for animal adenoviruses only the canine adenovirus 2 [19], fowl adenovirus 1 long and short fibre heads [20,21], the porcine adenovirus 4 fibre head and galectin domain structures [22] and the snake adenovirus 1 (SnAdV-1) fibre head [23] structures have been published, while well-diffracting crystals of the turkey adenovirus 3 fibre head have been obtained [24].

Atadenovirus is one of the five genera of the family Adenoviridae [1, 2, 25]. They are serologically and phylogenetically distinct from the other adenovirus genera, and their genomic organization also differs $[1,8,14$, 26]. Their capsids contain an extra protein (LH3), important for capsid stability [27]. Four trimeric LH3 knobs are present on each facet, with the LH3 protein being wedged in-between three hexon trimers. Atadenoviruses have been detected in a broad range of hosts, including predominantly scaled reptiles (order Squamata), as well as birds, ruminants and a marsupial [16, 26, 28-35]. So far, five species of atadenovirus have been confirmed: Snake atadenovirus $A$, Duck atadenovirus A, Bovine atadenovirus $D$, Ovine atadenovirus $D$ and Possum atadenovirus $A[2,3,36]$.

About half of identified ruminant adenoviruses are mastadenoviruses, while the remainder are atadenoviruses [2]. From the bovine adenoviruses, serotypes 1, 2, 3, 9 and 10 are mastadenoviruses [37, 38], while bovine adenoviruses $4,5,6,7$ and 8 are atadenoviruses $[39,40]$. Bovine adenovirus 4 (BAdV-4; strain THT/62) is the reference strain for the Bovine atadenovirus $D$ species and was first isolated and characterized in Hungary (GenBank accession number AF036092) [39, 41, 42]. BAdV-4 contains a single fibre gene, encoding a protein of 535 amino acids in length with low sequence identity to known adenovirus fibres (15$19 \%)$. Like other adenovirus fibres, it is predicted to consist of three domains: an N-terminal penton-base binding domain, a shaft domain and a C-terminal fibre head domain (Fig. 1b). Based on the location of the triple beta-spiral shaft repeats $[43,44]$, the N-terminal penton-base-binding domain of the fibre is proposed to contain amino acids $1-80$, while the $\mathrm{C}$-terminal fibre head domain was expected to start around residue 414. Here, we report the expression, purification, crystallization and structure solution of the fibre head domain of BAdV-4 at $1.2 \AA(0.12 \mathrm{~nm})$ resolution. It is the second atadenovirus fibre head structure that has been solved, after that of the SnAdV-1 fibre head domain [23]; and the first of an atadenovirus which infects mammalian cells. Although the secondary structure topology is the same as for other adenovirus fibre heads, differences are observed in the loops connecting the beta-strands and in the predicted surface charge. Our structure is a first step towards a better understanding of BAdV-4 host cell interaction, which, in turn, will have implications for the use of mammalian atadenovirus for medical purposes, be it in the use of whole viruses [14], or in chimeric fibres with atadenovirus fibre heads [45].

\section{Results and discussion}

Purification, crystallization and structure solution of the BAdV-4 fibre head

Sequence analysis suggested that residues 414-535 might form the C-terminal head domain. Therefore, expression vectors for the full-length sequence (1-535), a C-terminal fragment with part of the predicted shaft domain (residues 248-535) and the putative fibre head domain alone (amino acids 414-535) were constructed. All three constructs expressed the expected protein, but soluble protein was only obtained for the putative fibre head domain. Expression was carried out at low temperature and the protein was purified by metal affinity chromatography and ion exchange chromatography as described in the Methods section. In cation exchange chromatography, the protein 
eluted in five different peaks (Fig. 2). N-terminal sequence analysis by Edman degradation of protein from the five peaks yielded the same sequence (GSSHH), suggesting the $\mathrm{N}$-terminal six-histidine tags to be intact and the $\mathrm{N}$ terminal Met to be removed upon expression in E. coli. Mass spectrometry on protein from the five peaks suggested adducts of around 180 Dalton, which could correspond to spontaneous alpha- $N$-6-phosphogluconoylation of the six-histidine tag, as observed for other proteins with the same N-terminal six-histidine tag [46]. Multiple peaks eluting from cation chromatography were also observed for a different protein expressed in E. coli with the same Nterminal six-histidine tag [46]. Careful inspection of the gel in Fig. $2 \mathrm{~b}$ suggests the presence of two bands. The presence of two bands may well be caused by differential alpha- $N-6$ phosphogluconoylation. The fact that the protein is a trimer may lead to mixed species and thus the generation of the

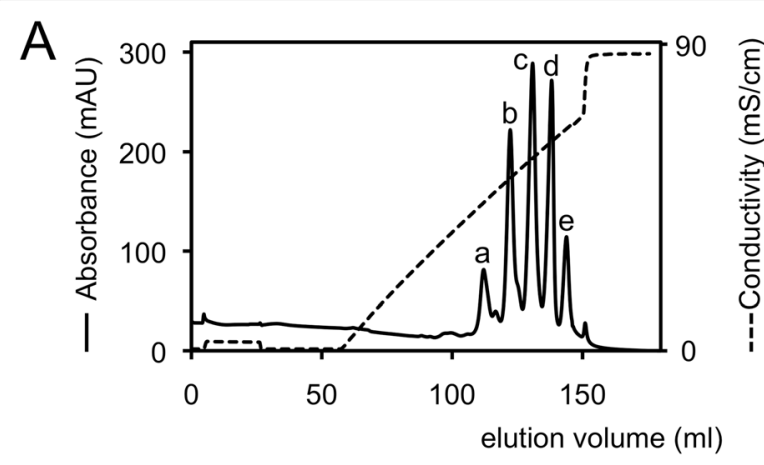

B
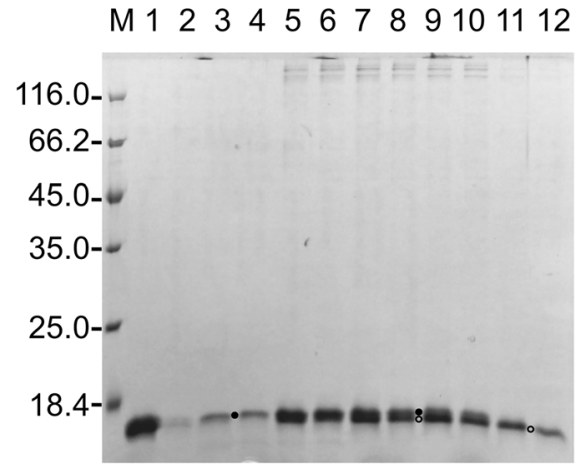

Fig. 2 Purification of BAdV-4 fibre head protein by cation exchange chromatography. a. Elution profile. The absorbance measured at $280 \mathrm{~nm}$ and the conductivity are shown. $\mathbf{b}$. Denaturing gel electrophoresis of peak fractions. In lane $\mathrm{M}$, molecular weight markers of the size (in $\mathrm{kDa}$ ) indicated on the left were loaded. In lane 1, an aliquot of the sample after nickel-affinity chromatography was loaded, eluted with imidazole. In lane 2, an aliquot of the sample eluted from the same column at $\mathrm{pH} 5$ was loaded. In lanes 3 and 4, lanes 5 and 6, lanes 7 and 8, lanes 9 and 10 and lanes 11 and 12 samples from peaks a, b, c, d and e were loaded, respectively. Samples in odd lanes were heated for 5 min at $95^{\circ} \mathrm{C}$ before loading, samples in even lanes were not. Putative upper and lower bands are indicated with filled and open circles, respectively. The protein runs as a monomer in all cases: the BAdV-4 fibre head does not form denaturant-stable trimers like other adenovirus fibre heads multiple peaks observed. The fact that the earlier peaks contain more adduct is consistent with the cation exchange chromatography behaviour, because the adduct would be expected to remove a positive charge and lead the protein to elute at lower salt concentrations. Protein from the three major peaks b, c and d was concentrated separately to $12 \mathrm{mg} / \mathrm{ml}$ (peaks a and e were considered to contain too little protein for successful crystallization). Around $13 \mathrm{mg}$ of purified protein in total was obtained per litre of expression culture. Adenovirus fibre heads eluting in several peaks from ion exchange chromatography has been observed before $[24,47]$.

Well-diffracting crystals were obtained from all of the three major cation exchange elution peaks at $21{ }^{\circ} \mathrm{C}$, by sitting drop vapour diffusion from precipitant solutions containing $20 \%$ poly-ethylene glycol 3350 and either $0.2 \mathrm{M}$ potassium thiocyanate or $0.2 \mathrm{M}$ sodium isothiocyanate. Crystals appeared after three days and grew to their maximal size in about three weeks. They were found to belong to space group $P 1$, with one protein trimer in the unit cell, leading to a solvent content of $44 \%$ and a Matthews coefficient of 2.2 [48]. A calculated selfrotation function confirmed the presence of noncrystallographic three-fold symmetry in the crystal. We were not successful in solving the structure by molecular replacement, although the availability of a high-quality isomorphous derivative dataset meant we did not pursue this method extensively. High-resolution isomorphous datasets were collected from the native and derivative crystals, and the derivative dataset contained high-quality anomalous signal, which allowed automated structure solution by single isomorphous replacement with anomalous dispersion. The final refined model contains residues $420-$ 534 from each of the three protein chains in the trimer, plus ordered solvent atoms. No reliable density was observed for the $\mathrm{N}$-terminal purification tag, for residues 414-419 or for the C-terminal glutamine (amino acid 535), suggesting that these are disordered. No differences were observed between crystallization success, crystal shape or form, for protein obtained from the 3 central peaks; which is consistent with that they presumably only differ in the adduct on the disordered N-terminal purification tag, for which there is room in the crystal lattice. The non-observed residues 414-419 may form a linker between the shaft and head domain in the intact fibre protein. Data collection, phasing and refinement statistics are shown in Table 1.

\section{Overall structure}

The structure of the BAdV-4 fibre head domain is composed of three monomers, associated into a compact trimer (Fig. 3). Each monomer consists of a beta-sandwich of two beta-sheets (ABCJ- and GHID-sheets; Fig. 3a), in the same topology (Fig. 3c) as other adenovirus fibre 
Table 1 Crystallographic data collection, phase determination, solvent flattening and refinement statistics (all values in parenthesis are for the highest resolution bin)

\begin{tabular}{|c|c|c|}
\hline Data collection & Native & Derivative \\
\hline Cell parameters $(a, b, c)(\AA)$ & $43.3,48.2,52.1$ & $43.4,48.4,52.6$ \\
\hline Cell parameters $(a, \beta, \gamma)\left(^{\circ}\right)$ & $117.1,95.6,110.2$ & $116.9,95.8,110.2$ \\
\hline Wavelength $(\AA)$ & 0.9763 & 1.0023 \\
\hline Resolution ( $\AA$ ) & $44.2-1.17(1.21-1.17)$ & $26.2-1.40(1.42-1.40)$ \\
\hline Observed reflections & 103174 (9613) & $62174(2058)$ \\
\hline Multiplicity & $3.6(3.5)$ & $3.4(3.2)$ \\
\hline Completeness (\%) & $91.2(86.7)$ & $92.6(61.0)$ \\
\hline Rmerge (\%) & $3.6(43.1)$ & $4.8(22.4)$ \\
\hline$<\mid /$ sigma $(\mid)>$ & $15.7(2.6)$ & $12.5(3.8)$ \\
\hline Wilson $B\left(\AA^{2}\right)$ & 10.5 & 12.0 \\
\hline $\mathrm{CC} 1 / 2$ & $1.000(0.842)$ & $0.995(0.894)$ \\
\hline CCanom & $-0.078(0.008)$ & $0.442(0.131)$ \\
\hline \multicolumn{3}{|l|}{ Phase determination } \\
\hline Number of heavy atom sites & & $6 \mathrm{Hg}$ \\
\hline Phasing power (isomorphous/anomalous) & & $2.290 / 1.716$ \\
\hline Figure of merit & & 0.601 \\
\hline \multicolumn{3}{|l|}{ Solvent flattening (40.8 \% solvent) } \\
\hline Hand score (original/inverted) & & $0.3647 / 0.8403$ \\
\hline Overall correlation on $|\mathrm{E}|^{2} /$ contrast & & 2.6012 \\
\hline \multicolumn{3}{|l|}{ Refinement } \\
\hline Resolution range $(\AA ̊)$ & $44.2-1.17(1.22-1.17)$ & \\
\hline No. reflections used in refinement & $100391(11648)$ & \\
\hline No. reflections used for R-free & $2782(311)$ & \\
\hline R-factor (\%) & $11.6(21.7)$ & \\
\hline R-free (\%) & $14.6(23.9)$ & \\
\hline No. of protein/solvent atoms & $2841 / 448$ & \\
\hline Average B protein/solvent atoms $\left(\AA^{2}\right)$ & $18.7 / 35.5$ & \\
\hline Ramachandran plot (favoured/allowed) (\%) & 98.0/99.7 & \\
\hline R.m.s. deviation of bonds $(\AA)$ and angles $\left({ }^{\circ}\right)$ & $0.012 / 1.5$ & \\
\hline PDB code & 4UEO & \\
\hline
\end{tabular}

heads (the topology of the HAdV-5 fibre head is shown as an example in Fig. 3d) [7, 47, 49]. The same topology is also shared with reovirus fibre heads $[50,51]$, the bacteriophage PRD1 fibre head [52] and lactobacillus phage receptor-binding domains [53, 54], as previously described [23]. The loop between strands D and G is longer than the others and contains an alpha helix (residues 471-476), instead of the E- and F-strands that many mastadenovirus fibre head domains have in this loop (Fig. 3d) [49]. The A-, B-, G- and H-strands are relatively long (eight, ten, nine and 13 residues, respectively), while the C-, D-, I- and J-strands are shorter (six, five, six and six residues, respectively). The AB-, BC-, GHand HI-loops are short beta-turns of four amino acids each, while the CD-, DG- and IJ-loops are longer (twelve, 16 and 14 residues, respectively). Similar as observed for other adenovirus fibre heads, the CD- and IJloops are located at the top of the fibre head, whereas the DG-loop is located on the side. All are potentially involved in receptor interactions. The CD- and IJ-loops run parallel to each other and contain negatively charged residues, forming electronegative patches on the protein surface (Fig. 4a). The CD- and IJ-loops are also involved in inter-monomer contacts with the J-strand of the neighbouring monomer.

The two beta-sheets of the BAdV-4 fibre head monomer face each other at an angle of around $120^{\circ}$. The ABCJ-sheet is mostly on the "inside", and only a part of the $A B$ beta-hairpin is solvent-accessible. The rest of the $\mathrm{AB}$ beta-hairpin and the whole $\mathrm{C}$ - and J-strands are 


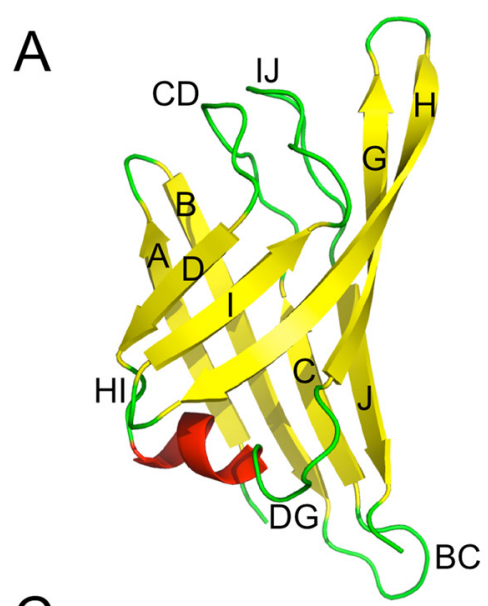

C

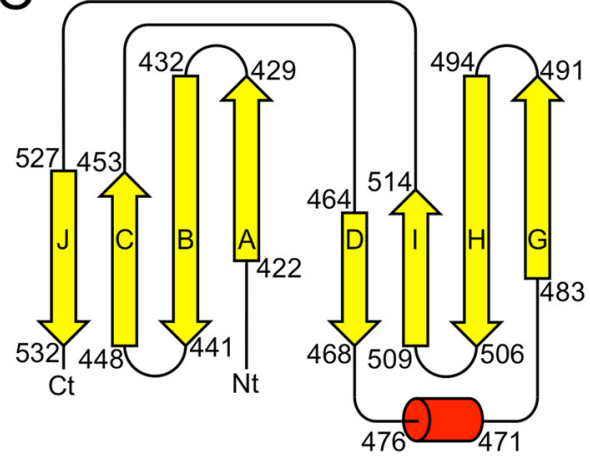

$E$

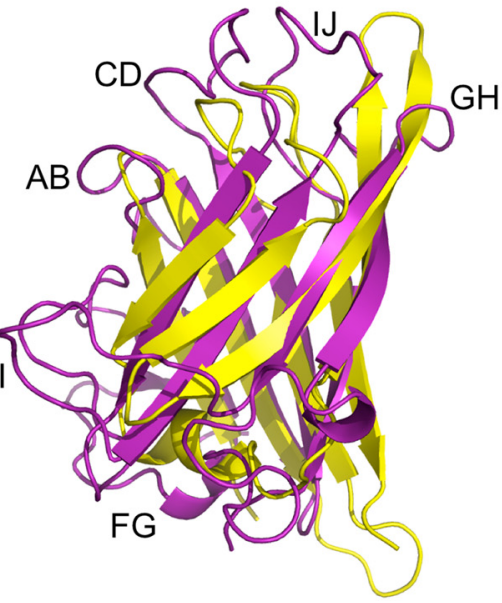

B

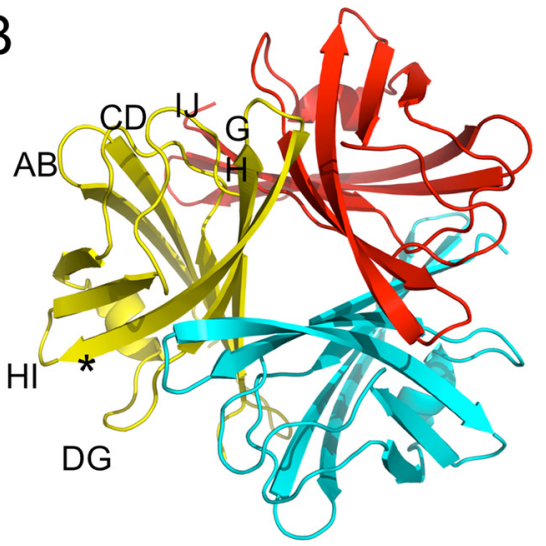

D

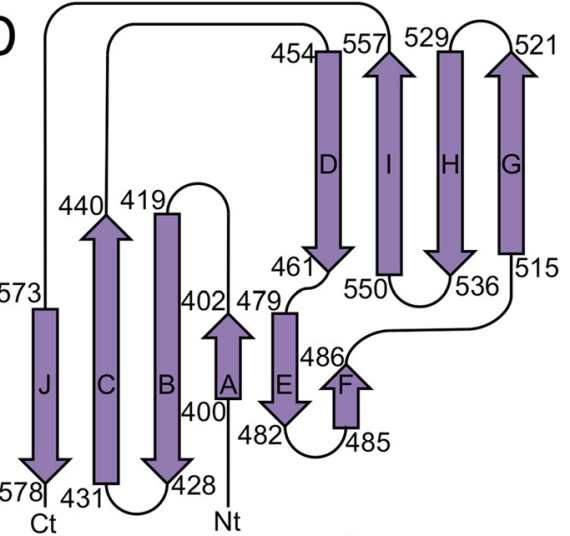

$\mathrm{F}$

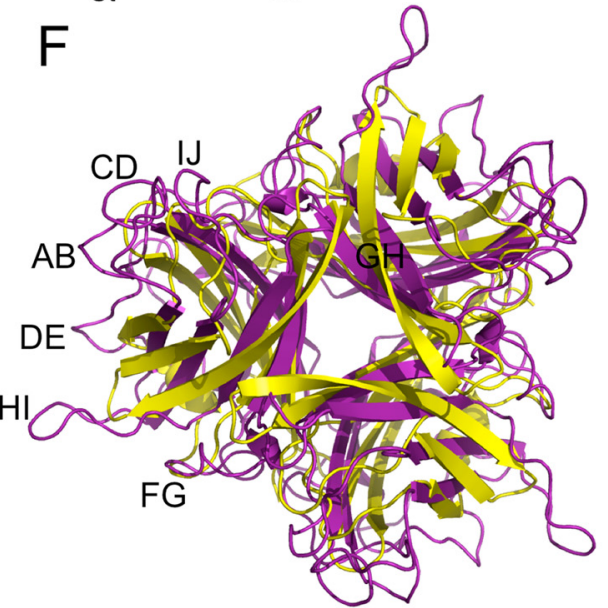

Fig. 3 Structure of the BAdV-4 fibre head domain. a. Monomer structure coloured by secondary structure. Beta-strands and most of the loops are labelled. b. Top view of the trimer with the three monomers coloured differently. An asterisk indicates the GHID-sheet in the yellow monomer and most loops are labelled. c. Topology diagram of the BAdV-4 fibre head, with start and end residues of each beta-strand and of the alpha-helix labelled. $\mathbf{d}$. Topology diagram of the HAdV-5 fibre head, shown for comparison. e. Superposition of the HAdV-5 fibre head monomer onto the BAdV-4 fibre head monomer in the same orientation as part A. f: Superposition of the HAdV-5 fibre head trimer onto the BAdV-4 fibre head trimer (top view). Surface loops of the HAdV-5 fibre head trimer are indicated

buried and extensively involved in inter-monomer contacts. In contrast, most of the GHID-sheet is solventaccessible (Fig. 3b). Together with the alpha-helix, the two beta-sheets from each monomer form a compact globular trimeric beta-propellor.

\section{Comparison with other adenovirus fibre heads}

Mastadenovirus fibre heads are larger than atadenovirus fibre heads, as previously described [23], mainly due to the surface loops being longer. The AB-, CD-, DG-, HI- and IJloops are all shorter in the BAdV-4 fibre head than in the 

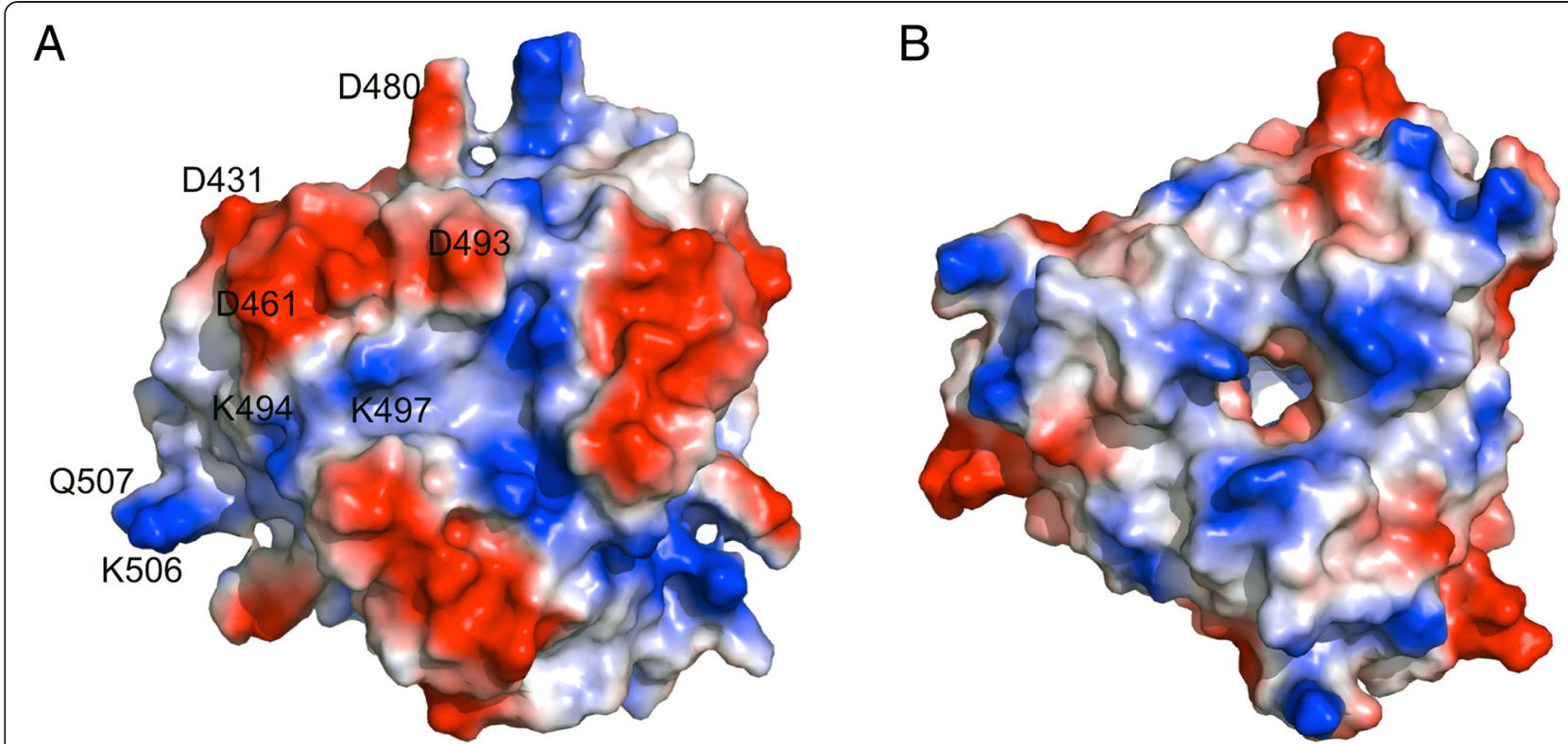

Fig. 4 Qualitative electrostatic surface of the BAdV-4 fibre head trimer (a) and SnAdV-1 fibre head trimer (b) seen from the top. Some BAdV-4 fibre head surface residues that are expected to have negative or positive charges are labelled

prototype mastadenovirus fibre head structure, HAdV-5. Exceptions are strands $\mathrm{G}$ and $\mathrm{H}$ and the BC-loop, which are longer in the BAdV-4 fibre head. The low similarity of the structures makes it impossible to make meaningful speculations about receptor binding.

The BAdV-4 fibre head shares only $15 \%$ sequence identity with the other atadenovirus fibre head (from SnAdV-1) for which a structure is known [23]. Nevertheless, the structure is very similar (Fig. 5). This is surprising considering that today one of these viruses exists in cattle (after a supposed host switch from reptiles) [31, 55] and the other still in snakes, with which they presumably continuously co-evolved. The two trimers can be superposed with an overall Z-score of 13 and a root mean square deviation (r.m.s.d.) of around $2 \AA$. When monomers are superposed, the r.m.s.d. is only slightly lower (1.8 $\AA$ ), indicating that the relative orientation of the monomers in the trimer is also very similar. The topologies of both fibre heads are identical, with a conserved beta-sandwich motif and an alphahelix in the DG-loop. Both fibre heads share the same $120^{\circ}$ angle between two beta-sheets, but differences are observed in the length and the conformation of the loops.

The CD- and IJ-loops of the BAdV-4 fibre head are longer than those in the SnAdV-1 fibre head. In contrast, the DG-loop of the BAdV-4 fibre head is two amino acids shorter than its SnAdV-1 counterpart. A noticeable difference is observed in the length of the G- and H-strands, which are quite a bit longer in the BAdV-4 fibre head (9 vs. 5 for the G-strand and 13 vs. 8 residues for the $\mathrm{H}$-strand). As mentioned before, the CD-, IJ- and GH-loops are all located on the top of the molecule, while the DG-loop is on the side, making all of them potentially important for receptor interaction. In a structure-based alignment (Fig. 5c), the lack of sequence similarity becomes even more evident, except for the very C-terminal part of the protein (end of the $\mathrm{H}$-strand and the I- and J-strands and the HI-turn). It may be speculated that this conserved part of the protein is important for initiation of protein folding and has therefore diverged less. When calculated electrostatic surfaces are considered, the BAdV-4 fibre head has distinct electronegatively charged patches on its surface (Fig. 4a), while the SnAdV-1 surface is more electro-positive (Fig. 4b) [23]. This may have implications for receptor-binding and suggest they do not bind the same receptor, although the nature of the receptors for neither of the viruses is known.

From previous observations in other adenoviruses, the BAdV-4 fibre head was expected to be a stable protein. However, unlike other head domains such as that of the fowl adenovirus 1 long fibre [56] and of the SnAdV-1 fibre [57], this trimer is not denaturant-stable at room temperature (Fig. 2b). Its melting temperature, as measured by a thermofluor assay, was estimated to be $67^{\circ} \mathrm{C}$, which is relatively high. In the same assay, no unfolding transition was observed for the SnAdV-1 fibre head below $95^{\circ} \mathrm{C}$, confirming the SnAdV-1 fibre head is more stable. Each monomer has a total solvent accessible surface area of $6.6 \times$ $10^{3} \AA^{2}$, out of which $0.62 \times 10^{3} \AA^{2}(9 \%)$ gets buried upon trimer formation. In the SnAdV-1 fibre head, about 1.5 times more surface area is buried [23]. No salt bridges are formed upon trimeric assembly for the BAdV-4 fibre head, while in the SnAdV-1 fibre head a strong bidentate salt bridge between Arg304 and Glu333 of neighbouring 


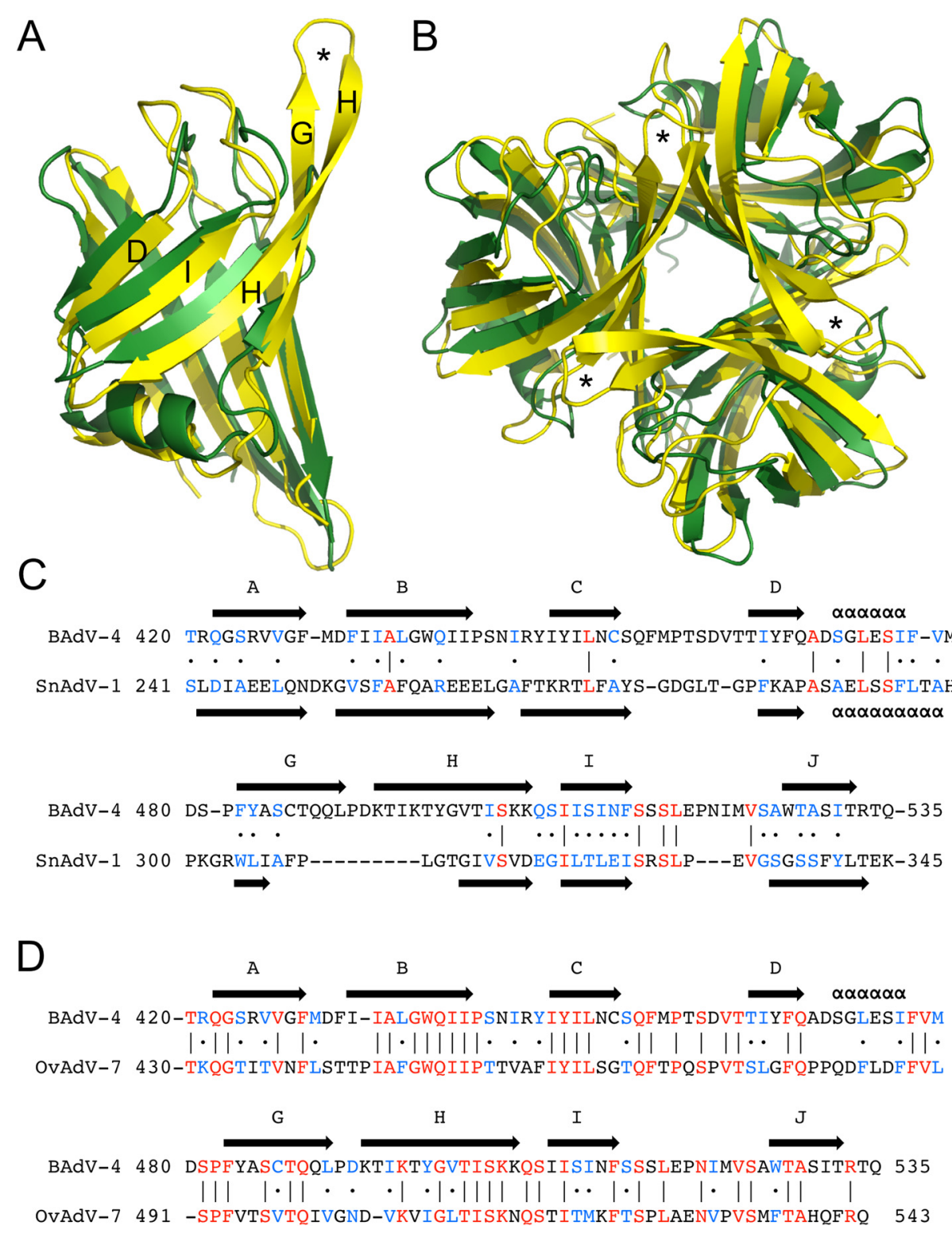

Fig. 5 Comparison of the BAdV-4 fibre head with other atadenovirus fibre heads. a. Superposition of the BAdV-4 monomer onto the SnAdV-1 monomer (same orientation as in Fig. 3a). The BAdV-4 fibre head is shown in yellow and the SnAdV-1 fibre head in dark-green. The strands of the GHID-sheet are labelled. $\mathbf{b}$. Superposition of the BAdV-4 trimer onto the SnAdV-1 trimer (same orientation as in Figs. $3 \mathbf{b}$ and $\mathbf{f}$, top view). The colours are as in panel A. In panels A and B, asterisks indicate the location of the GH-loops. c. Structure-based sequence alignment of the BAdV-4 and SnAdV-1 fibre head sequences. Strands are indicated with arrows and labelled; alpha-helices are indicated with a's. Similar residues are coloured blue and indicated with the symbol · (a dot); identical residues coloured red and marked with the symbol | (a line). d. Sequence alignment of the BAdV-4 and OAdV-7 fibre head sequences

monomers is present, which may explain why the SnAdV-1 fibre head is more stable than the BAdV-4 fibre head. Table 2 lists the identified interactions, from which it can be concluded that the SnAdV-1 fibre head has more hydrophobic, aromatic and ionic interactions between monomers, while the number of inter-monomer hydrogen bonds is the same.

Ovine adenovirus 7 (OAdV-7), another ruminant atadenovirus, is intensively tested as a basis for a gene therapy vector [16], but the structure of its fibre head is unknown. Our BAdV-4 fibre head structure is likely similar to that of the OAdV-7 fibre head [27], with which it shares $44 \%$ sequence identity (51 out of 116 amino acids; Fig. 5d). It should now be possible to build a reliable structural model of the OAdV-7 fibre head in order to identify surface residues possibly involved in receptor binding and mutating them. Our cloning, expression and crystallization strategy may also be used to obtain 
Table 2 Potential inter-monomer interactions of atadenovirus fibre heads

\begin{tabular}{|c|c|c|}
\hline & SnAdV-1 fibre head & BAdV-4 fibre head \\
\hline \multirow{13}{*}{$\begin{array}{l}\text { Hydrophobic } \\
\text { interactions (<5 } \AA \text { ) }\end{array}$} & Leu265 - Ala245 & Ile445 - Val246 \\
\hline & Phe268 - Ala245 & Tyr484 - Ile496 \\
\hline & Phe268 - Ala257 & Tyr484 - Met523 \\
\hline & Pro301 - Tyr276 & \\
\hline & Leu306 - Pro310 & \\
\hline & Leu306 - Leu311 & \\
\hline & Ala308 - Pro310 & \\
\hline & Phe340 - Phe274 & \\
\hline & Phe340 - Tyr276 & \\
\hline & Tyr341 - Tyr276 & \\
\hline & Leu342 - Ala257 & \\
\hline & Leu342 - Phe274 & \\
\hline & Leu342 - Tyr276 & \\
\hline \multirow[t]{8}{*}{ Hydrogen bonds } & Lys239NZ - Ser2410 & Arg446NH2 - Leu436O \\
\hline & Lys239NZ - Asp243OD2 & Pro482O - Gln482NE2 \\
\hline & Lys270NZ - Gln2590E1 & Tyr484N - Gln455OE1 \\
\hline & Lys302NZ - Gly2780 & Tyr484OH - Gln490N \\
\hline & Arg304NH1 - Glu333OE1 & Tyr484OH - Thr488OG1 \\
\hline & Arg304NH1 - Glu333OE2 & Ser530O - Gln455N \\
\hline & Arg304NH2 - Glu333OE1 & Ser5300G - Ser454OG \\
\hline & Phe340N - Ser336OG & Thr532OG1 - Ser454OG \\
\hline \multirow{5}{*}{$\begin{array}{l}\text { lonic interactions } \\
(<6 \AA)\end{array}$} & Lys239 - Asp243 & \\
\hline & Glu263 - Arg261 & \\
\hline & Lys302 - Asp279 & \\
\hline & Lys302 - Glu333 & \\
\hline & Arg304 - Glu333 & \\
\hline \multirow{3}{*}{$\begin{array}{l}\text { Aromatic interactions } \\
(4.5-7 \AA)\end{array}$} & Phe340 - Phe274 & \\
\hline & Phe340 - Tyr276 & \\
\hline & Tyr341 - Tyr276 & \\
\hline $\begin{array}{l}\text { Cation-pi interactions } \\
(<6 \AA)\end{array}$ & Lys270 - Phe274 & \\
\hline
\end{tabular}

The first residue is from chain $A$, the second from chain $B$ of the trimer; letters behind the residue number indicate the atom, where appropriate

crystals for the OAdV-7 fibre head, and the structure determined experimentally by molecular replacement using data collected on these crystals.

\section{Conclusion}

The high resolution structure of BAdV-4 fibre head is the second solved structure of an atadenovirus fibre head domain. However, it is the first fibre head structure of an atadenovirus which infects a mammalian host. The structure showed that the atadenovirus fibre head structure is conserved, including the alpha-helix in the DG-loops, between two species infecting very different hosts, even though the sequence identity is very low. Differences in the conformation of surface loops and in the predicted surface charge may be of importance for primary receptor recognition.

\section{Methods}

\section{Cloning, expression and purification}

BAdV-4 strain THT/62 [39] was propagated on primary or low-passage-number calf testis cell cultures, then the virus was purified by ultracentrifugation, and the DNA extracted as described earlier [41]. Three genome fragments, coding for the full BAdV-4 fibre protein or parts of it containing the putative head domain (UniProt Q997H2) were amplified from the extracted viral DNA (GenBank accession No AF036092) [58] by polymerase chain reaction (PCR) using three forward primers including a BamHI restriction site and a reverse primer with a HindIII restriction site. The amplified PCR products were cloned into the expression vector pET28a(+) (Novagen, Merck, Darmstadt, Germany), previously digested with the same restriction enzymes. The inserts of the resulting plasmids were sequenced and found to be correct. The pET28a(+) vector provides an N-terminal six-histidine tag.

For protein expression, E. coli strain JM109(DE3) was transformed with the respective expression vector and bacteria were grown aerobically at $37^{\circ} \mathrm{C}$ until the optical density at $600 \mathrm{~nm}$ reached $0.5-0.8$. At this point, the culture was cooled on ice for $30 \mathrm{~min}$, IPTG was added to a final concentration of $0.5-1 \mathrm{mM}$ and aerobic growth was continued for $18-20 \mathrm{~h}$ at $16^{\circ} \mathrm{C}$. Cells from 21 of culture were harvested by centrifugation $(10 \mathrm{~min}$ $5000 \times g)$, re-suspended in buffer A $(10 \mathrm{mM}$ Tris- $\mathrm{HCl}$ $\mathrm{pH}$ 7.5, $0.5 \mathrm{M}$ sodium chloride, $10 \%(\mathrm{v} / \mathrm{v})$ glycerol) including $20 \mathrm{mM}$ imidazole and stored at $-20{ }^{\circ} \mathrm{C}$. After thawing, cells were lysed by two passes through a French press at about $7 \mathrm{MPa}$. Cell rests were removed by centrifugation for $30 \mathrm{~min}$ at $20000 \times g$.

For purification, $2 \mathrm{ml}$ of nickel-NTA resin slurry (BioRad, Madrid, Spain) was added to the proteincontaining supernatant and incubated with occasional gentle shaking for $30 \mathrm{~min}$ on ice. The resin was then transferred to a column and washed with $30 \mathrm{ml}$ of buffer A with $20 \mathrm{mM}$ imidazole. BAdV-4 fibre protein variants were eluted using a step-gradient of imidazole in buffer A $(50 \mathrm{mM}, 100 \mathrm{mM}, 250 \mathrm{mM}$ and $500 \mathrm{mM}$ imidazole; steps of $5 \mathrm{ml}$ ). After analysis by denaturing gel electrophoresis, fractions containing 100-500 mM imidazole were pooled, dialysed against $20 \mathrm{mM}$ MES pH 6.5 and loaded onto a Resource S6 column (GE-Healthcare Biosciences, Uppsala, Sweden). The protein was eluted with a linear gradient of $0-1 \mathrm{M}$ sodium chloride in $20 \mathrm{mM}$ MES $\mathrm{pH}$ 6.5. Fractions containing pure protein were 
concentrated to $18 \mathrm{mg} / \mathrm{ml}$ using an Amicon Ultra concentrator with a molecular weight cut-off of $10 \mathrm{kDa}$ (Millipore, Madrid, Spain). Three washes with $10 \mathrm{ml}$ $10 \mathrm{mM}$ Tris- $\mathrm{HCl} \mathrm{pH} 7.5,50 \mathrm{mM}$ sodium chloride and $5 \%(\mathrm{v} / \mathrm{v})$ glycerol were applied. The sample was stored at $4{ }^{\circ} \mathrm{C}$ prior to crystallization trials.

\section{Thermofluor assay}

A thermal shift assay [59] was carried out in an iCycler iQ PCR Thermal Cycler (Bio-Rad, Hercules CA, USA) in the presence of the fluorescent dye SYPRO Orange (Life Technologies SA, Madrid, Spain). Reaction volumes of $30 \mu \mathrm{l}$ were prepared in $200 \mu \mathrm{l}$ with $30 \mu \mathrm{g}$ of protein and 5X SYPRO Orange from the supplied 5000X stock solution. Thermal denaturation curves were obtained by heating the samples from $20{ }^{\circ} \mathrm{C}$ to $95{ }^{\circ} \mathrm{C}$ with a ramp rate of $1{ }^{\circ} \mathrm{C} / \mathrm{min}$ and monitoring the fluorescence at every $0.5{ }^{\circ} \mathrm{C}$ increment. The melting temperature $\mathrm{Tm}$ is defined as the point where the slope of the fluorescence increase is maximal.

\section{Crystallization, crystallographic data collection and structure solution}

The BAdV-4 fibre head protein was crystallized using the sitting drop vapour diffusion method (robotic setup with a Genesis RSP 150 workstation; Tecan, Männedorf, Switzerland or by manual setup). In either case, $50 \mu \mathrm{l}$ of reservoirs were employed, and drops were prepared containing $0.2 \mu \mathrm{l}$ of protein sample and $0.2 \mu \mathrm{l}$ of the respective reservoir solution for robotic setups and $0.6 \mu \mathrm{l}$ of protein plus $0.6 \mu \mathrm{l}$ of reservoir for manual setups. Crystals were harvested with Litholoops (Molecular Dimensions, Newmarket, England) or Micromounts (Mitegen, Ithaca, New York, USA), transferred to cryo-protection solution (reservoir solution containing $20 \%(\mathrm{v} / \mathrm{v})$ glycerol) and flash-cooled in liquid nitrogen.

A heavy atom derivative was prepared by adding a few grains of methylmercury chloride to the reservoir of one drop and letting the drop equilibrate with the reservoir overnight. Two $\mu \mathrm{l}$ of reservoir solution was then added to the drop and incubated for about $5 \mathrm{~min}$. The crystal was harvested in cryo-solution without methylmercury chloride as described for the native.

Crystallographic data were collected from a native and a methylmercury chloride derivative crystal at the BL13-XALOC beamline of the ALBA synchrotron [60], using a wavelength at which significant anomalous signal from the added mercury atoms was expected (1.0023 ^). Later, a higher-resolution native dataset was collected at beamline ID29 of the ESRF [61]. Crystallographic data collected at BL13-XALOC were integrated using iMosflm [62] and further processed using POINTLESS, AIMLESS and TRUNCATE
[63] from the CCP4-suite [64]. Data collected at ID29 were processed using XDS [65, 66], analyzed using AIMLESS and processed by TRUNCATE to obtain structure factor amplitudes. A self-rotation function was calculated with MOLREP [67].

Structure solution was done using AUTOSHARP [68], which employs SHELX for heavy atom positions substructure determination [69], SHARP for phase determination [70] and SOLOMON for solvent flattening [71]. Reflections were selected in thin shells for calculation of Rfree [72]. Phases from AUTOSHARP were combined with the structure factor amplitudes from the high-resolution native dataset and input into ARPWARP for automated model building [73]. This obtained model was completed using COOT [74] and structure refined using REFMAC5 [75], including anisotropic temperature factor refinement. Validation was done with MOLPROBITY [76]. Structure comparisons, including r.m.s.d. and Z-score calculations, were performed using the DALI server [77]. Figures were made using PYMOL (The PYMOL Molecular Graphics System, Version 1.5.0.4. Schrödinger, LLC). Protein assembly parameters were calculated using PISA [78] and individual interactions identified with PIC [79].

\section{Competing interests}

The authors declare that they have no competing interests.

\section{Authors' contributions}

MZV constructed the expression vector and AKS, THN and MZB performed the first expression trials. THN purified and crystallized the protein with help of AKS. THN, MS-G and MJVR collected and processed X-ray diffraction data. THN and MJVR performed structure solution, refinement and analyzed the structure. MB, BH and MJvR supervised the project. THN and MJVR wrote the manuscript and made the figures, all authors helped to improve the manuscript and approved the final version. All authors read and approved the final manuscript.

\section{Acknowledgements}

We thank Javier Varela (CIB-CSIC) for N-terminal sequence analysis, Sergio Ciordia, Mari Carmen Mena and Alberto Paradela for mass spectrometry, Carmen San Martín for careful reading of the manuscript and Jordi Benach (ALBA beamline BL13/XALOC) and Christoph Mueller-Dieckmann (ESRF beamline ID29) for help with using synchrotron data collection facilities. We acknowledge ALBA/CELLS and the European Synchrotron Radiation Facility for access, which contributed to the results presented here. The research leading to these results was sponsored by grant BFU2011-24843 (to MJVR, THN, MSG and AKS) from the Spanish Ministry of Economy and Competitiveness, a VAST-CSIC PhD fellowship to THN, a FEMS short-term Research Fellowship award to MZB, a RISAM fellowship to MSG, a La Caixa fellowship to AKS, and by grant OTKA NN107632 from the Hungarian Scientific Research Fund (to BH).

\section{Author details}

'Departamento de Estructura de Macromoleculas, Centro Nacional de Biotecnologia (CNB-CSIC), calle Darwin 3, 28049 Madrid, Spain. ${ }^{2}$ Institute for Veterinary Medical Research, Centre for Agricultural Research, Hungarian Academy of Sciences, Budapest, Hungary. ${ }^{3}$ Department of Biological Sciences, Cork Institute of Technology, Bishopstown, Cork, Ireland. ${ }^{4}$ Current address: School of Biosciences, Stacey Building, University of Kent, Canterbury, Kent, CT2 7NJ, United Kingdom. 


\section{References}

1. Davison AJ, Benkő M, Harrach B. Genetic content and evolution of adenoviruses. J Gen Virol. 2003;84(Pt 11):2895-908.

2. Harrach B, Benkő M, Both GW, Brown M, Davison AJ, Echavarría M, et al. Family Adenoviridae. In: King AMQ, Adams MJ, Carstens EB, Lefkowitz EJ, editors. Virus taxonomy: classification and nomenclature of viruses. Ninth report of the international committee on taxonomy of viruses. New York: Elsevier; 2011. p. 125-41.

3. Harrach B. Adenoviruses: general features. In Reference Module in Biomedical Sciences. Elsevier (2014), doi:10.1016/B978-0-12-801238-3.02523-X.

4. Harrach B. Available adenovirus sequences. http://www.vmri.hu/ harrach/ ADENOSEQ.HTM. Accessed 25 Feb 2015.

5. Wold WS, Horwitz MS. Adenoviruses. In: Fields BN, Knipe DM, Howley PM, editors. Fields virology. 5th edition. Philadelphia: Wolters Kluwer Health/ Lippincott Williams \& Wilkins; 2007. p. 2395-436.

6. Benkő M. Adenoviruses: pathogenesis. In: Mahy BWJ, van Regenmortel MHV editors. Encyclopedia of virology, 5 vols. Third edition, vol.1. Oxford: Elsevier; 2008. p. 24-9.

7. San Martin C. Latest insights on adenovirus structure and assembly. Viruses. 2012;4(5):847-77

8. Pénzes JJ, Menendez-Conejero R, Condezo GN, Ball I, Papp T, Doszpoly A, et al. Molecular characterization of a lizard adenovirus reveals the first atadenovirus with two fiber genes and the first adenovirus with either one short or three long fibers per penton. J Virol. 2014;88(19):11304-14.

9. Sharma A, Li X, Bangari DS, Mittal SK. Adenovirus receptors and their implications in gene delivery. Virus Res. 2009;143(2):184-94.

10. Wolfrum N, Greber UF. Adenovirus signalling in entry. Cell Microbiol. 2013:15(1):53-62

11. Ariza L, Giménez-Llort L, Cubizolle A, Pagès G, García-Lareu B, Serratrice N, et al. Central nervous system delivery of helper-dependent canine adenovirus corrects neuropathology and behavior in mucopolysaccharidosis type VII mice. Hum Gene Ther. 2014:25(3):199-211.

12. Arnberg N. Adenovirus receptors: implications for tropism, treatment and targeting. Rev Med Virol. 2009;19(3):165-78.

13. Bachtarzi H, Stevenson M, Fisher K. Cancer gene therapy with targeted adenoviruses. Expert Opin Drug Del. 2008:5(11):1231-40.

14. Both GW, Cameron F, Collins A, Lockett LJ, Shaw J. Production and release testing of ovine atadenovirus vectors. Methods Mol Med. 2007:130:69-90.

15. Nicklin SA, Wu E, Nemerow GR, Baker AH. The influence of adenovirus fibe structure and function on vector development for gene therapy. Mol Ther. 2005;12:384-93

16. Tang R, Li K, Wilson M, Both GW, Taylor JA, Young SL. Potent anti-tumor immunity in mice induced by vaccination with an ovine atadenovirus vector. J Immunother. 2012;35(1):32-41.

17. Thacker EE, Timares L, Matthews QL. Strategies to overcome host immunity to adenovirus vectors in vaccine development. Expert Rev Vaccines. 2009:8(6):761-77.

18. Lopez-Gordo E, Podgorski II, Downes N, Alemany R. Circumventing antivector immunity: potential use of nonhuman adenoviral vectors. Hum Gene Ther. 2014;25(4):285-300.

19. Seiradake E, Lortat-Jacob H, Billet O, Kremer EJ, Cusack S. Structural and mutational analysis of human Ad37 and canine adenovirus 2 fiber heads in complex with the D1 domain of coxsackie and adenovirus receptor. J Biol Chem. 2006;281(44):33704-16.

20. Guardado-Calvo P, Llamas-Saiz AL, Fox GC, Langlois P, van Raaij MJ. Structure of the C-terminal head domain of the fowl adenovirus type 1 long fibre. J Gen Virol. 2007;88(Pt 9):2407-16.

21. El Bakkouri M, Seiradake E, Cusack S, Ruigrok RW, Schoehn G. Structure of the C-terminal head domain of the fowl adenovirus type 1 short fibre. Virology. 2008;378(1):169-76.

22. Guardado-Calvo P, Muñoz EM, Llamas-Saiz AL, Fox GC, Kahn R, Curiel DT et al. Crystallographic structure of porcine adenovirus type 4 fiber head and galectin domains. J Virol. 2010;84(20):10558-68

23. Singh AK, Menéndez-Conejero R, San Martín C, van Raaij MJ. Crystal structure of the fibre head domain of the atadenovirus snake adenovirus 1 PLoS One 2014:9(12):e114373.

24. Singh AK, Ballmann MZ, Benkő M, Harrach B, van Raaij MJ. Crystallization of the C-terminal head domain of the fibre protein from a siadenovirus, turkey adenovirus 3. Acta Cryst F. 2013;69(10):1135-9.

25. Benkő M, Harrach B. A proposal for establishing a new (third) genus within the Adenoviridae family. Arch Virol. 1998;143:829-37.
26. Farkas SL, Benkő M, Élő P, Ursu K, Dán A, Ahne W, et al. Genomic and phylogenetic analyses of an adenovirus isolated from a corn snake (Elaphe guttata) imply a common origin with members of the proposed new genus Atadenovirus. J Gen Virol. 2002:83(Pt 10):2403-10.

27. Pantelic RS, Lockett LJ, Rothnagel R, Hankamer B, Both GW. Cryoelectron microscopy map of Atadenovirus reveals cross-genus structural differences from human adenovirus. J Virol. 2008;82(15):7346-56

28. Ascher JM, Geneva AJ, Ng J, Wyatt JD, Glor RE. Phylogenetic analyses of novel squamate adenovirus sequences in wild-caught Anolis lizards. PLoS One. 2013:8(4):e60977.

29. Ball I, Behncke H, Schmidt V, Geflügel FT, Papp T, Stöhr AC, et al. Partial characterization of new adenoviruses found in lizards. J Zoo Wildl Med. 2014;45(2):287-97.

30. Harrach B, Meehan BM, Benkő M, Adair BM, Todd D. Close phylogenetic relationship between egg drop syndrome virus, bovine adenovirus serotype 7, and ovine adenovirus strain 287. Virology. 1997;229(1):302-6.

31. Harrach B. Reptile adenoviruses in cattle? Acta Vet Hung. 2000;48(4):485-90.

32. Papp T, Fledelius B, Schmidt V, Kaján GL, Marschang RE. PCR-sequence characterization of new adenoviruses found in reptiles and the first successful isolation of a lizard adenovirus. Vet Microbiol. 2009;134(3-4):233-40.

33. Thomson D, Meers J, Harrach B. Molecular confirmation of an adenovirus in brushtail possums (Trichosurus vulpecula). Virus Res. 2002;83(1-2):189-95.

34. To KK, Tse H, Chan WM, Choi GK, Zhang AJ, Sridhar S, et al. A novel psittacine adenovirus identified during an outbreak of avian chlamydiosis and human psittacosis: zoonosis associated with virus-bacterium coinfection in birds. PLoS Negl Trop Dis. 2014;8(12):e3318.

35. Wellehan JFX, Johnson AJ, Harrach B, Benkő M, Pessier AP, Johnson CM, et al. Detection and analysis of six lizard adenoviruses by consensus primer PCR provides further evidence of a reptilian origin for the atadenoviruses. J Virol. 2004;78(23):13366-9.

36. International Committee on Taxonomy of Viruses, http://www.ictvonline.org Accessed 25 Feb 2015

37. Evans PS, Benkő M, Harrach B, Letchworth GJ. Sequence, transcriptional analysis, and deletion of the bovine adenovirus type 1 E3 region. Virology. 1998;244(1):173-85.

38. Ursu K, Harrach B, Matiz K, Benkő M. DNA sequencing and analysis of the right-hand part of the genome of the unique bovine adenovirus type 10 . J Gen Virol. 2004;85(Pt 3):593-601

39. Bartha A, Áldásy P. Further two serotypes of bovine adenovirus (serotype 4 and 5). Acta Vet Hung Acad Sci. 1966;16(1):107-8.

40. Élő P, Farkas SL, Dán AL, Kovács GM. The p32K structural protein of the atadenovirus might have bacterial relatives. J Mol Evol. 2003:56(2):175-80.

41. Dán ÁL, Ruzsics ZS, Russell WC, Benkő M, Harrach B. Analysis of the hexon gene sequence of bovine adenovirus type 4 provides further support for a new adenovirus genus (Atadenovirus). J Gen Virol. 1998;79(6):1453-60.

42. Dán ÁL, Élő P, Harrach B, Zádori Z, Benkő M. Four new inverted terminal repeat sequences from bovine adenoviruses reveal striking differences in the length and content of the ITRs. Virus Genes. 2001:22(2):175-9.

43. Chroboczek J, Ruigrok RW, Cusack S. Adenovirus fiber. Curr Top Microbiol Immunol. 1995:199(Pt 1):163-200.

44. van Raaij MJ, Mitraki A, Lavigne G, Cusack S. A triple beta-spiral in the adenovirus fibre shaft reveals a new structural motif for a fibrous protein Nature. 1999;401(6756):935-8

45. Renaut L, Colin M, Leite JP, Benkő M, D'Halluin JC. Abolition of hCARdependent cell tropism using fiber knobs of Atadenovirus serotypes. Virology. 2004;321(2):189-204

46. Geoghegan KF, Dixon HB, Rosner PJ, Hoth LR, Lanzetti AJ, Borzilleri KA, et al. Spontaneous a-N-6-phosphogluconoylation of a "His Tag" in Escherichia coli: the cause of extra mass of 258 or $178 \mathrm{Da}$ in fusion proteins. Anal Biochem. 1999;267(1):169-84

47. Van Raaij MJ, Louis N, Chroboczek J, Cusack S. Structure of the human adenovirus serotype 2 fibre head domain at $1.5 \AA$ resolution. Virology. 1999:262(2):333-43.

48. Matthews BW. Solvent content of protein crystals. J Mol Biol. 1968;33(2):491-7.

49. Xia D, Henry LJ, Gerard RD, Deisenhofer J. Crystal structure of the receptorbinding domain of adenovirus type 5 fibre protein at $1.7 \AA$ resolution. Structure. 1994;2(12):1259-70.

50. Chappell JD, Prota AE, Dermody TS, Stehle T. Crystal structure of reovirus attachment protein sigma1 reveals evolutionary relationship to adenovirus fiber. EMBO J. 2002;21(1-2):1-11. 
51. Guardado Calvo P, Fox GC, Hermo Parrado XL, Llamas-Saiz AL, Costas C, Martinez-Costas J, et al. Structure of the carboxy-terminal receptor-binding domain of avian reovirus fibre sigmaC. J Mol Biol. 2005;354(1):137-49.

52. Merckel MC, Huiskonen JT, Bamford DH, Goldman A, Tuma R. The structure of the bacteriophage PRD1 spike sheds light on the evolution of viral capsid architecture. Mol Cell. 2005;18(2):161-70.

53. Spinelli S, Campanacci V, Blangy S, Moineau S, Tegoni M, Cambillau C. Modular structure of the receptor binding proteins of Lactococcus lactis phages. The RBP structure of the temperate phage TP901-1. J Biol Chem. 2006;281(20):14256-62.

54. Spinelli S, Desmyter A, Verrips CT, Dehaard HJ, Moineau S, Cambillau C. Lactococcal bacteriophage p2 receptor-binding protein structure suggests a common ancestor gene with bacterial and mammalian viruses. Nat Struct Mol Biol. 2006;13(1):85-9

55. Benkő M, Harrach B. Molecular evolution of adenoviruses. Curr Top Microbiol Immunol. 2003;272:3-35.

56. Guardado-Calvo P, Llamas-Saiz AL, Langlois $P$, van Raaij MJ. Crystallization of the C-terminal head domain of the avian adenovirus CELO long fibre. Acta Cryst F. 2006;62(5):449-52.

57. Singh AK, Menéndez-Conejero R, San Martín C, van Raaij MJ. Crystallization of the C-terminal domain of the fibre protein from snake adenovirus 1, an atadenovirus. Acta Cryst F. 2013;69(12):1374-9.

58. Dán A, Benkő M, Harrach B. Analysis of the complete DNA sequence of bovine adenovirus type 4 confirms the genome organization characteristic of the proposed new genus atadenovirus, vol. V-916. Paris: Abstracts of the XII. International Congress of Virology; 2002. p. 308.

59. Lavinder JJ, Hari SB, Sullivan BJ, Magliery TJ. High-throughput thermal scanning: a general, rapid dye-binding thermal shift screen for protein engineering. J Am Chem Soc. 2009;131(11):3794-5.

60. Juanhuix J, Gil-Ortiz F, Cuni G, Colldelram C, Nicolas J, Lidon J, et al. Developments in optics and performance at BL13-XALOC, the macromolecular crystallography beamline at the Alba Synchrotron. J Synchrotron Rad. 2014;21(Pt 4):679-89.

61. de Sanctis D, Beteva A, Caserotto H, Dobias F, Gabadinho J, Giraud T, et al. ID29: a high-intensity highly automated ESRF beamline for macromolecular crystallography experiments exploiting anomalous scattering. J Synchrotron Radiat. 2012;19(Pt 3):455-61.

62. Battye TG, Kontogiannis L, Johnson O, Powell H, Leslie AG. iMOSFLM: a new graphical interface for diffraction-image processing with MOSFLM. Acta Cryst D. 2011;67(Pt 4):271-81.

63. Evans PR. An introduction to data reduction: space-group determination, scaling and intensity statistics. Acta Crystallogr D Biol Crystallogr. 2011:67(Pt 4):282-92

64. Winn MD, Ballard CC, Cowtan KD, Dodson EJ, Emsley P, Evans PR, et al. Overview of the CCP4 suite and current developments. Acta Cryst D. 2011;67(Pt 4):235-42

65. Kabsch W. XDS. Acta Crystallogr D Biol Crystallogr. 2010;66(Pt 2):125-32.

66. Kabsch W. Integration, scaling, space-group assignment and postrefinement. Acta Crystallogr D Biol Crystallogr. 2010;66(Pt 2):133-44.

67. Vagin A, Teplyakov A. Molecular replacement with MOLREP. Acta Cryst D. 2010;66(Pt 1):22-5

68. Vonrhein C, Blanc E, Roversi P, Bricogne G. Automated structure solution with autoSHARP. Meth Mol Biol. 2007;364:215-30.

69. Sheldrick GM. Experimental phasing with SHELXC/D/E: combining chain tracing with density modification. Acta Cryst D. 2010;66(Pt 4):479-85.

70. de la Fortelle E, Bricogne G. Maximum-likelihood heavy-atom parameter refinement for multiple isomorphous replacement and multiwavelength anomalous diffraction methods. Meth Enzymol. 1997:276:472-94.

71. Abrahams JP, Leslie AG. Methods used in the structure determination of bovine mitochondrial F1 ATPase. Acta Cryst D. 1996;52(Pt 1):30-42.

72. Brunger AT. Free R value: a novel statistical quantity for assessing the accuracy of crystal structures. Nature. 1992;355(6359):472-5.

73. Langer G, Cohen SX, Lamzin VS, Perrakis A. Automated macromolecular model building for $X$-ray crystallography using ARP/WARP version 7 Nat Protoc. 2008;3(7):1171-9.

74. Emsley P, Lohkamp B, Scott WG, Cowtan K. Features and development of Coot. Acta Crystallogr D Biol Crystallogr. 2010;66(Pt 4):486-501.

75. Murshudov GN, Skubak P, Lebedev AA, Pannu NS, Steiner RA, Nicholls RA, et al. REFMAC5 for the refinement of macromolecular crystal structures. Acta Crystallogr D Biol Crystallogr. 2011;67(Pt 4):355-67.
76. Chen VB, Arendall WB, Headd JJ, Keedy DA, Immormino RM, Kapral GJ, et al. MolProbity: all-atom structure validation for macromolecular crystallography. Acta Cryst D. 2010;66(Pt 1):12-21.

77. Holm L, Rosenstrom P. Dali server: conservation mapping in 3D. Nucl Acids Res. 2010;38(Web Server issue):W545-9.

78. Krissinel $E_{1}$ Henrick K. Inference of macromolecular assemblies from crystalline state. J Mol Biol. 2007;372:774-97.

79. Tina KG, Bhadra R, Srinivasan N. PIC: protein interactions calculator. Nucl Acids Res. 2007;35(Web Server issue):W473-6.

\section{Submit your next manuscript to BioMed Central and take full advantage of:}

- Convenient online submission

- Thorough peer review

- No space constraints or color figure charges

- Immediate publication on acceptance

- Inclusion in PubMed, CAS, Scopus and Google Scholar

- Research which is freely available for redistribution 